\title{
ПРОТОКОЛЫ СЛЕДСТВЕННЫХ ДЕЙСТВИЙ И СУДЕБНОГО ЗАСЕДАНИЯ ПО УГОЛОВНОМУ ДЕЛУ: ПОСТАНОВКА ПРОБЛЕМЫ
}

\begin{abstract}
Аннотация. В статье аргументируется необходимость исследования протоколов следственных действий и судебного заседания как доказательств по уголовному делу. На основании многочисленных отечественных работ по уголовно-процессуальному праву дореволюционного, советского, а также современного периода делается вывод о явно недостаточном научном внимании к данной проблематике. Автор полагает, что в настоящее время в науке уголовного процесса наметилась определенная тенденция, направленная на более детальное исследование протоколов следственных действий и судебного заседания как доказательств по уголовному делу. Однако вопрос об их использовании в доказывании проработан в гораздо меньшей степени, по сравнению, например, с показаниями, заключениями эксперта или вещественными доказательствами. В этой связи предпринята попытка наметить определенные направления для дальнейшего развития этой научной проблемы с целью совершенствования процессуального законодательства и правоприменительной практики.

Ключевые слова: доказательство, доказывание, следственные действия, судебное заседание, уголовно-процессуальное законодательство, следователь, суд, судебное производство, процессуальное действие, вещественное доказательство. DOI: 10.7256/1729-5920.2014.2.8887
\end{abstract}

$\mathrm{Y}$ головно-процессуальное законодательство Российской Федерации в качестве одного из видов доказательств предусматривает протоколы следственных действий и судебного заседания ${ }^{1}$ (п. 5 ч. 2 ст. 74, ст. 83 УПК РФ). Как известно - это доказательства, сопряженные с непосредственным восприя-

Необходимо обратить внимание на некоторую законодательную неточность, допущенную при формулировании взаимосвязанных положений п. 5 ч. 2 ст. 74 и ст. 83 УПК РФ в части судебных действий. Так, в первом случае закон говорит о протоколах судебных действий, а во втором - о едином протоколе судебного заседания. Представляется очевидным, что правильной является формулировка, содержащаяся в ст. 83 УПК РФ, поскольку все действия, происходящие в судебном заседании (за исключением, пожалуй, лишь судебной экспертизы) находят свое отражение в едином процессуальном документе - протоколе судебного заседания. В этой связи мы будем придерживаться именно формулировки «протоколы следственных действий и судебного заседания». А причины, побудившие к появлению отмеченной законодательной неточности, и возможные варианты ее преодоления будут рассмотрены в дальнейшем. тием дознавателем, следователем или судом сведений, имеющих значение для уголовного дела. Нередко с их помощью удается установить и обосновать такие обстоятельства и факты, имеющие значение для уголовного дела, которые не могут быть доказаны иными процессуальными средствами.

Протоколы используются и в досудебном, и в судебном производстве. Однако в процессе предварительного расследования каждое процессуальное действие фиксируется самостоятельным протоколом, а в ходе судебного разбирательства все процессуальные действия - одним общим протоколом судебного заседания.

Вместе с тем в научных работах, посвященных доказательственному праву, протоколы следственных действий и судебного заседания традиционно не привлекали и до настоящего времени не привлекли должного внимания исследователей. Они ограничивались и продолжают ограничиваться лишь по-

(C) Россинский Сергей Борисович

* Кандидат юридических наук, доцент кафедры уголовно-процессуального права Московского государственного юридического университета имени О.Е. Кутафина (МГЮА)

[s.rossinskiy@gmail.com]

123995, Москва, ул. Садовая-Кудринская, д. 9. 
нятием протоколов следственных действий и судебного заседания по уголовному делу, а также перечнем самих процессуальных действий, обусловливающих появление данного вида доказательств ${ }^{2}$. Отдельные авторы также затрагивали вопросы использования в доказывании наглядных приложений к протоколам следственных действий и судебного заседания (фотоснимков, аудиозаписи и т.д.) $)^{3}$. И, наконец, в некоторых работах, посвященных данной проблематике, акцентируется внимание на правилах составления протоколов следственных действий и судебного заседания как на условиях допустимости данного вида доказательств ${ }^{4}$. Остальные вопросы продолжают оставаться вне предмета многочисленных научных публикаций. Так, до настоящего времени малоисследованной остается сущность протоколов следственных действий и судебного заседания, в частности характер и значение запечатленной в них доказательственной информации. Практически не рассмотрены проблемы соотношения протоколов следственных действий и судебного заседания с другими видами уголовно-процессуальных доказательств - показаниями, вещественными доказательствами и иными документами. Явно недостаточно научного внимания уделялось основным свойствам указанных протоколов: относимости, достоверности и допустимости. Не определено их соотношение с близкими по сути непроцессуальными средствами познания - результатами оперативно-розыскной и административной деятельности.

Отсутствие выработанных теоретических подходов к доказательственной сущности рассматриваемых протоколов, пробелы в их

\footnotetext{
2 Чельцов М.А. Уголовный процесс. М., 1948. С. 326; Строгович М.С. Курс советского уголовного процесса. Т. 1. М., 1968. С. 458; Курс советского уголовного процесса. Общая часть / под ред. А.Д. Бойкова, И.И. Карпеца. М., 1989. С. 602-603; Кокорев Л.Д., Кузнецов Н.П. Уголовный процесс: доказательства и доказывание. Воронеж, 1995. С. 216-217; Ульянова Л.Т. Предмет доказывания и доказательства в уголовном процессе России. М., 2008. С. 120-121; Орлов Ю.К. Проблемы теории доказательств в уголовном процессе. М.: Юристъ, 2009. С. 161-162 и др.

Галкин В.М. Средства доказывания в уголовном процессе. М., 1967. С. 44-47; Божьев В.П., Лубенский А.И. Источники доказательств по уголовно-процессуальному законодательству СССР и других социалистических государств. М., 1981. С. 66-67; Лазарева В.А. Доказывание в уголовном процессе. М., 2009. С. 326-327.

4 Теория доказательств в советском уголовном процессе / отв. ред. Н.В. Жогин. М., 1973. С. 674-680; Кипнис Н.M. Допустимость доказательств в уголовном судопроизводстве. М., 1995. С. 69.
}

правовой регламентации неизбежно приводят к серьезным затруднениям, возникающим в повседневной правоприменительной деятельности органов дознания и предварительного следствия, судов и прочих участников производства по уголовному делу.

Что же из себя представляют протоколь следственных действий и судебного заседания в системе средств процессуального познания в настоящее время? Какие следственные и судебные действия обусловливают появление данного вида доказательств?

Анализ русской дореволюционной литературы показывает, что первые взгляды и суждения отечественных исследователей, посвященные изучению данной процессуальной тематики, появились на рубеже XIX-XX столетий. Это произошло в то время, когда в Российской империи уже была наработана определенная практика применения буржуазного уголовно-процессуального законодательства смешанного типа, позволившая выявить целый ряд теоретических и прикладных проблем. В отечественной процессуальной науке наметились отдельные тенденции, направленные на их изучение и разрешение. Однако это были только первые шаги на пути от эмпирии к теории. Воззрения ученых о сущности и доказательственном значении письменных документов, в частности протоколов следственных действий и судебного заседания, находились еще в самом зачаточном состоянии и, конечно, во многом не соответствовали современным представлениям. Как справедливо отмечал М.М. Выдря, в связи с принятием в 1864 г. Устава уголовного судопроизводства некоторые дореволюционные юристы начали глубже разрабатывать вопросы теории доказательств, однако документам не было уделено должного внимания 5 .

Все существовавшие в дореволюционной России научные позиции по поводу использования в доказывании по уголовным делам протоколов следственных действий и судебного заседания можно условно разделить на две большие группы.

Представители первой группы преимущественно воздерживались от каких-либо суждений и комментариев относительно сущности и доказательственного значения протоколов следственных действий и судебного заседания в уголовном судопроизводстве. В работах они упоминали об этих документах лишь вскользь, не раскрывая их содержания.

Выдря М.М. Вещественные доказательства в советском уголовном процессе. М., 1955. С. 46. 
Так, С.В. Познышев ограничивался кратким суждением, что письменные доказательства могут быть записями, изложениями и описаниями тех или иных доказательственных фактов, собранных органами предварительного производства (например, разные протоколы осмотров, обысков и т.п.) $)^{6}$.

С.И. Викторский, ограничиваясь цитированием Устава уголовного судопроизводства, писал, что если стороны того потребуют или признают это нужным судьи или присяжные, то в судебном заседании могут быть прочитаны протоколы об осмотрах, освидетельствованиях, обысках и выемках ${ }^{7}$. Причем к этой же категории документов, имеющих значение непосредственных доказательств по делу, по его мнению, принадлежали и письма, заметки, написанные подсудимым, и всякого рода другие частные бумаги, служащие к обвинению или оправданию подсудимого ${ }^{8}$.

М.В. Духовской в курсе лекций по уголовному процессу, написанном для студентов Московского университета, упоминал, что протоколы осмотров, обысков и выемок могут быть оглашены в судебных заседаниях так же, как и остальные протоколы, когда этого требуют стороны или найдет нужным суд 9 .

Вторую группу, по нашему мнению, составляют взгляды и воззрения дореволюционных специалистов, предпринимавших отдельные попытки исследования сущности и значения протоколов следственных действий и судебного заседания как доказательств по уголовному делу. Так, И.Я. Фойницкий, выделяя протоколы осмотра и освидетельствования из других письменных доказательств, пытался определить основания и порядок их использования в судебном заседании, оценить значение по уголовному делу. Он писал, что наибольшую доказательственную силу практика признает за протоколами судебного заседания ${ }^{10}$.

Г.С. Фельдштейн утверждал, что письменными доказательствами в собственном смысле являются разного рода протоколы, под которыми нужно разуметь известную запись, составленную по установленной форме

6 Познышев С.В. Элементарный учебник русского уголовного процесса. М., 1913. С. 201.

Викторский С.И. Русский уголовный процесс. М., 1912. С. 297.

\section{Там же. С. 297-298.}

Духовской М.В. Русский уголовный процесс. М., 1910. С. 243.

10 Фойницкий И.Я. Курс уголовного судопроизводства. Т. 2. СПб., 1996. С. 308-309, 311-312. официальным органом и содержащую в себе отчет о действиях этого органа по поводу какого-либо события. Они возможны в самых разнообразных формах: протоколы, составленные полицией и другими административными властями; все акты предварительного следствия; протоколы судебного заседания и пр. ${ }^{11}$ При этом автор рассматривал протоколы вкупе с другими письменными документами, не проводя между ними более или менее четкой границы.

Наибольшую же историческую ценность, на наш взгляд, представляет фундаментальная работа Л.Е. Владимирова «Учение об уголовных доказательствах», в которой он дает понятие судебного протокола. Таковым, по его мнению, следует считать отчет, составленный компетентным лицом на месте, с соблюдением предписанных законом правил для установления каких-либо фактов, имеющих значение обстоятельств судебного дела. При этом в качестве признаков такого протокола автор выделял: а) необходимость его составления надлежащим лицом ${ }^{12}$; б) необходимость его составления на месте; в) необходимость его подписания наряду с составителем, свидетелями его составления (понятыми. - C.P.) $)^{13}$. Все судебные протоколы Л.Е. Владимиров подразделял на три группы: протоколы - поводы к началу предварительного расследования (сообщения полиции, явки с повинной и т.д.); протоколы следственных действий и протоколы судебного заседания ${ }^{14}$.

Резюмируя изложенные научные позиции, можно прийти к некоторым выводам о взглядах дореволюционных ученых по поводу сущности и значения протоколов следственных действий и судебного заседания как доказательств по уголовному делу. Во-первых, очевидна весьма слабая теоретическая разработанность данной проблемы. Bсе приведенные суждения (в том числе и позиции представителей второй группы, которые несомненно продвинулись в рассмотрении этих

\footnotetext{
11 Фельдштейн Г.С. Лекции по уголовному судопроизводству. М., 1915. С. 292-293.

12 Л.Е. Владимиров в принципе не исключал и возможности, при наличии особых обстоятельств, составления судебных протоколов иными, специально не уполномоченными на это лицами. По его мнению, такие протоколы вполне могли использоваться в процессе доказывания по уголовному делу как частные письменные документы, доказательственная сила которых должна была определяться по внутреннему усмотрению судьи.

13 Владимиров Л.Е. Учение об уголовных доказательствах. Части общая и особенная. СПб., 1910. С. 354-355.

14 Там же. С. 355-359.
} 
вопросов гораздо дальше) носили достаточно отрывистый, бессистемный характер. Вовторых, дореволюционные юристы вообще не считали протоколы следственных действий и судебного заседания самостоятельным видом (источником) доказательств, а рассматривали их как разновидность письменных документов, исходящих от определенных государственных органов и содержащих определенные сведения. В-третьих, под протоколами следственных действий прежде всего понимались именно протоколы осмотра и освидетельствования. Хотя дореволюционному уголовному процессу были известны и иные следственные действия - обыск и выемка. Причина представляется вполне ясной: осмотры и освидетельствования (кстати, как и сейчас) связаны в первую очередь с визуальным восприятием какого-либо места, объекта или человека. Причем обнаружение и изъятие в ходе их производства каких-либо предметов потенциальных вещественных доказательств возможно, но совсем не обязательно. Обыск или выемка, наоборот, направлены именно на изъятие подобных объектов.

Таким образом, вывод напрашивается сам собой: видимо, дореволюционные специалисты не дифференцировали вещественные доказательства и следственные действия, направленные на их обнаружение и изъятие. Иными словами, результат обыска или выемки и объекты, изъятые в ходе их производства, рассматривались как единое целое вещественное доказательство. Кстати, на этот фракт обращал внимание и М.М. Выдря. Он писал, что в дореволюционной литературе господствующей была точка зрения, согласно которой за документами самостоятельного значения в уголовном процессе не признавалось; они, как правило, относились к вещественным доказательствам ${ }^{15}$

Дореволюционные специалисты опирались в первую очередь на действовавший в то время процессуальный закон - Устав уголовного судопроизводства Российской империи. Этот нормативный акт, как известно, в качестве самостоятельного вида (источника) выделял лишь вещественные доказательства (ст. 371). Никаких доказательств - протоколов он не предусматривал ${ }^{16}$. В этой связи следует

\footnotetext{
15 Выдря М.М. Указ. соч. С. 47.

16 Устав уголовного судопроизводства Российской империи вообще не содержал какого-либо систематизированного перечня доказательств по уголовному делу. Впервые такой перечень был дан в ст. 58 УПК РСФСР 1923 г.
}

отметить, что уголовно-процессуальные кодексы ряда стран, в том числе действующие и поныне, также не предусматривают среди доказательств протоколов следственных и судебных действий. В частности, подобная законодательная конструкция используется в УПК Федеративной Республики Германии ${ }^{17}$.

Несмотря на всю слабость теоретической разработанности данной проблемы, представляется очевидным одно существенное обстоятельство: российской дореволюционной науке был известен механизм формирования доказательств посредством составления протоколов определенных процессуальных действий. Под такими протоколами ученые справедливо понимали подлежащие последующему оглашению в суде письменные уголовно-процессуальные акты, в которых фиксировалась информация, полученная в результате собственных и преимущественно в последующем невосполнимых действий полиции, следователя или иных официальных лиц.

Анализ советской процессуальной литературы, до- и послевоенного периодов показал, что не произошло существенных сдвигов в отношении к доказательственной сущности протоколов следственных действий и судебного заседания. Представляется, что внимание к ним со стороны ученых было вынужденным и обусловливалось появлением в ст. 58 действовавшего тогда УПК РСФСР 1923 г. в качестве одного из видов (источников) доказательств протоколов осмотров и иных письменных документов. Поэтому советские специалисты, в отличие от дореволюционных, зачастую вообще не признававших подобного вида доказательств, просто не могли обойти данный объект стороной. Однако на этом их интерес к проблеме, как правило, заканчивался. Советскую процессуальную школу в первую очередь интересовали проблемы показаний обвиняемого и свидетелей, заключения эксперта и вещественные доказательства ${ }^{18}$.

Протоколы следственных действий и судебного заседания рассматривались вкратце,

17 Бойльке В. Уголовно-процессуальное право ФРГ / пер. с нем.; под ред. Л.В. Майоровой. Красноярск, 2004. C. 116 .

18 Вышинский А.Я. Теория судебных доказательств в советском праве. М., 1950. С. 259-285; Рахунов Р.Д. Теория и практика экспертизы в советском уголовном процессе. М., 1953. С. 7-66; Выдря М.М. Указ. соч. С. 5-56; Мотовиловкер Я.О. Показания и объяснения обвиняемого как средство защиты в советском уголовном процессе. М., 1956. С. 5-51; Каминская В.И. Показания обвиняемого в советском уголовном процессе. М., 1960. С. 19-92 и др. 
да еще и в совокупности с другими письменными доказательствами. Зачастую специалисты просто ограничивались пересказом соответствующей статьи УПК. Подобную конструкцию можно встретить в довоенных работах М.C. Строговича или послевоенных трудах М.Л. Якуба ${ }^{19}$. Некоторые авторы, в частности А.Я. Вышинский и М.М. Выдря, просто старались обойти протоколы следственных действий судебного заседания своим вниманием.

Тем не менее в советской литературе до- и послевоенного периода все же можно отметить некоторые попытки, направленные на изучение доказательственной сущности протоколов в уголовном судопроизводстве. Так, М.А. Чельцов писал об актах и протоколах судебно-следственных органов как об особом виде письменных доказательств, заменяющих на суде иные источники доказательств - вещественные доказательства и показания свидетелей, прочтение которых служит вместо судебного осмотра и допроса. Далее он указывал, что их оглашение может иметь место либо при противоречии устных показаний на суде с показаниями, ранее запротоколированными, либо при отсутствии устных показаний за смертью свидетеля, невозможностью его явки или отказом обвиняемого от дачи показаний ${ }^{20}$.

Очень близкую позицию занимала в то время Л.Т. Ульянова, говоря о том, что особенностью протоколов следственных и судебных действий является их производность от других источников доказательств (протокол допроса - от показаний свидетеля или обвиняемого; протокол осмотра - от обстановки и вещественных доказательств на месте происшествия и т.д.) $)^{21}$.

Мы не можем согласиться с такой точкой зрения, в данной ситуации налицо некоторое смешение протоколов следственных действий и судебного заседания как вида доказательств по уголовному делу с их содержанием, в том числе с информацией, подлежащей оглашению в судебном заседании, в частности с показаниями потерпевшего и свидетеля.

Однако все же необходимо признать стремление задать научный импульс для дальнейшего развития рассматриваемой проблемы.

9 Якуб М.Л. Вещественные и письменные доказательства // Вопросы уголовного процесса в практике Верховного Суда СССР. М., 1955. С. 209.

20 Чельцов М.А. Указ. соч. С. 327.

21 Ульянова Л.Т. Оценка доказательств судом первой инстанции. М., 1959. С. 165.
О производном характере протоколов писал В.Я. Лившиц22. Кстати, в этой связи весьма любопытным является предложенное им обоснование своей позиции. Он отмечал, что в советском уголовном процессе центр тяжести лежит на судебном разбирательстве как главной стадии процесса, в которой суд непосредственно воспринимает и проверяет доказательства, служащие основанием судебного приговора. Именно такое исследование, производимое судом в судебном заседании, лучше всего соответствует выполнению тех задач, которые стоят перед советским судом, в первую очередь - отысканию материальной истины по делу. При этом В.Я. Лившиц указывал, что в буржуазном уголовном процессе эпохи империализма широко проявляются различные заимствования из арсенала инквизиционного процесса и возврат к нему. А под такими заимствованиями автор, в частности, понимал и проведение судебного следствия исключительно путем ознакомления суда с протоколами предварительного следствия без непосредственного заслушивания устных показаний ${ }^{23}$.

Оценивая данную точку зрения, вынуждены констатировать ее политическую окраску, стремление автора пуститься из крайности в крайность, идеализировать советское правосудие, превознести его перед иными, буржуазными формами судопроизводства. Результат остается тем же: В.Я. Лившиц, как и другие упомянутые авторы, явно обесценивал протоколы следственных действий, придавая им второстепенный характер.

Комплексный анализ изложенных позиций позволяет констатировать весьма слабый научный интерес специалистов-процессуалистов до- и послевоенного периода к проблеме использования в доказывании по уголовным делам протоколов следственных действий и судебного заседания. Общее отношение к протоколам как к доказательствам в науке осталось прежним. Не была разорвана совершенно необоснованная связь между протоколами и иными используемыми в доказывании письменными документами: справками, характеристиками и тому подобными объектами. Наметившиеся тенденции к развитию данной процессуальной проблематики, на наш взгляд, были ошибочными: во-первых, обусловливали смешение различных видов доказательств как между собой, так и с содер-

22 Лившиц В.Я. Принцип непосредственности в советском уголовном процессе. М., 1949. С. 118.

23 Там же. С. 135. 
жавшейся в них доказательственной информацией; во-вторых, были направлены на их явное обесценивание, изначально закрепление за ними производного характера. Более того, намеченные тенденции во многом обусловливались политическим заказом, стремлением превознести советское правосудие. Поэтому очевидно, что рано или поздно они были обречены на провал.

Серьезным импульсом для развития проблемы использования в доказывании по уголовным делам протоколов следственных действий и судебного заседания послужила проведенная на рубеже 50-60 гг. прошлого века реформа уголовно-процессуального законодательства СССР и союзных республик. Так, ст. 16 Основ уголовного судопроизводства Союза ССР и союзных республик 1958 г. $^{24}$ предусматривала в качестве одного из видов (источников) доказательств протоколы следственных и судебных действий. Аналогичные правовые нормы нашли свое отражение в уголовно-процессуальных кодексах союзных республик, в частности в ч. 2 ст. 69 УПК РСФСР 1960 г. Статья 87 УПК РСФСР раскрывала сущность протоколов следственных действий и судебного заседания.

Научная общественность бурно откликнулась на подобную законодательную новацию. Так, во втором томе коллективной монографии «Теория доказательств в советском уголовном процессе» (1967г) протоколам следственных действий и судебного заседания посвящен целый самостоятельный параграф. Под такими протоколами Г.М. Миньковский и В.Г. Танасевич - авторы данного параграфа - понимали письменные акты, составленные лицом, производящим дознание, следователем, прокурором, судом при производстве следственных и судебных действий по собиранию и проверке доказательств. При этом сразу же следовала совершенно справедливая оговорка, что к таковым относятся не все протоколы, а лишь те, которые фиксируют фактические данные, полученные составителем протокола в результате непосредственного наблюдения действий, явлений, материальной обстановки, следов. И, наконец, в отличие от своих предшественников авторы выделяют целый ряд особенностей, характеризующих протоколы как самостоятельный вид (источник) доказательств: а) фиксируют целенаправленную деятельность органов расследования; б) фиксируют длящуюся деятельность; в) не только их ис-

24 Ведомости Верховного Совета СССР. 1959. № 1. Ст. 15. пользование, но и составление носит процессуальный характер ${ }^{25}$.

В.М. Галкин отмечал, что исходя из особых условий формирования процессуальных документов, законодатель из всей группы документов выделяет протоколы следственных и судебных действий. Он же говорил, что доказательствами УПК РСФСР признает протоколы лишь тех следственных и судебных действий, во время которых фиксируются фракты, воспринимаемые органами расследования и суда непосредственно ${ }^{26}$

М.С. Строгович в своих более поздних работах также пересмотрел прежнюю позицию относительно сущности рассматриваемых протоколов и писал о них как об отдельном виде доказательств, удостоверяющих обстоятельства и факты, установленные при осмотре, освидетельствовании, выемке, обыске, задержании, предъявлении лица для опознания и производстве следственного эксперимента. При этом особо подчеркивал, что в эту группу закон выделяет именно те протоколы, в которых фриксируются определенные факты, фрактические обстоятельства, например то, что было обнаружено при осмотре места преступления, при обыске у обвиняемого. К ним не следует относить протоколы допросов, а также действий, фиксирующих выполнение определенных требований закона, без установления обстоятельств существа дела, например протокол ознакомления обвиняемого с материалами законченного дела ${ }^{27}$.

Примерно тех же взглядов придерживались И.М. Гуткин ${ }^{28}$, В.П. Божьев, А.И. Лубенский ${ }^{29}$ и иные специалисты, посвятившие работы проблемам уголовно-процессуального доказывания, в частности отдельным видам доказательств.

Анализ современной уголовно-процессуальной литературы показывает гораздо больший интерес ученых к проблемам использования в доказывании протоколов следственных действий и судебного заседания. На наш взгляд, подобная динамика связана в первую очередь с новыми подходами законодателя к сущности процессуального доказывания в целом и отдельным средствам доказывания в

\footnotetext{
25 Теория доказательств в советском уголовном процессе / отв. ред. Н.В. Жогин. Т. 2. М., 1967. С. 301-303.

26 Галкин В.М. Указ. соч. С. 43.

27 Строгович М.С. Указ. соч. С. 458.

28 Уголовный процесс / под ред. Б.А. Викторова. М., 1970. С. $140-141$.

29 Божьев В.П., Лубенский А.И. Указ. соч. С. 65-66.
} 
частности. Исходя из современного смешанного, но в то же время во многом стремящегося к состязательному, характера отечественного уголовного судопроизводства, новый импульс развития получили многие, казалось бы, достаточно привычные процессуальные принципы. В частности, особое внимание стало уделяться концепции свободы оценки доказательств, предполагающей изначальное гипотетическое равенство между всеми установленными законом средствами познания в уголовном процессе (ст. 17 УПК РФ). И это несмотря на то, что формально аналогичные правовые нормы существовали и ранее (например, ст. 57 УПК РСФСР 1923 г., ст. 71 УПК РСФСР 1960 г.).

В связи с отмеченной тенденцией современные ученые проводят более глубокий анализ сущности и значения протоколов следственных действий и судебного заседания как доказательств по уголовному делу, стремятся доказать их равноценность с такими доказательствами, как, например, показания, заключение эксперта или вещественные доказательства. Например, В.А. Лазарева применительно к протоколам следственных действий отмечает, что их содержанием являются удостоверенные ими факты и обстоятельства, обнаруженные органом расследования при производстве следственных действий. Особенностью протоколов следственных действий выступает то, что они отражают результаты непосредственного, чувственного восприятия дознавателем, следователем или прокурором следов, оставленных преступлением ${ }^{30}$.

Л.Т. Ульянова в последних работах пишет, что протоколы следственных и судебных действий - письменные акты, в которых дознаватель, следователь, прокурор, суд по предусмотренным законом правилам фиксирует прежде всего то, что фактически было сделано при осуществлении конкретного действия, в том числе факт применения технических средств, а также установленные на основе непосредственного восприятия сведения, имеющие значение для правильного разрешения дела ${ }^{31}$.

Аналогичной позиции придерживается Ю.К. Орлов. Он отмечает, что указанные в ст. 83 УПК РФ протоколы выделены в самостоятельный источник доказательств ввиду того, что в них фриксируются обстановка, предметы или явления, непосредственно воспринимаемые следователем, понятыми и другими

30 Лазарева В.А. Указ. соч. С. 324.

31 Ульянова Л.Т. Предмет доказывания и доказательства в уголовном процессе России. М., 2008. С. 120. участниками данного следственного действия, а также судом, если такие следственные действия проводятся в судебном заседании ${ }^{32}$.

Таким образом, в настоящее время прослеживается четкая тенденция, направленная на более детальный анализ протоколов следственных действий и судебного заседания как доказательств по уголовному делу в контексте их гипотетической равноценности с другими средствами процессуального познания. Мы уже отмечали, что несмотря на появившийся научный интерес к данным протоколам, этим видам доказательств уделяется явно недостаточно внимания; многие вопросы практически не исследованы.

Кстати, и в УПК РФ (ст. 83) данному виду доказательств посвящена лишь небольшая и явно расплывчатая формулировка. Подчас даже создается впечатление, что законодатель считает протоколы следственных действий и судебного заседания какими-то «не главными» средствами познания, не заслуживающими такого пристального внимания, как, например, показания, заключение эксперта или вещественные доказательства. Иными словами, несмотря на закрепленную в законе концепцию свободы оценки доказательств, предполагающую гипотетическую равнозначность всех средств процессуального познания, в реальности некоторым из них, в частности протоколам следственных действий и судебного заседания, предусмотренным ст. 83 УПК РФ, фрактически отводится явно второстепенное значение.

Это наглядно демонстрируют материалы современной правоприменительной практики, те процессуальные документы, которые предполагают изложение собранных по делу доказательств: приговоры судов, обвинительные заключения и т.д. Например, по приговору Московского городского суда Ш. признан виновным в совершении нескольких преступлений, предусмотренных различными частями ст. 290 УК РФ. Свое решение суд аргументировал целым рядом собранных по делу доказательств. Однако при этом имеющиеся показания обвиняемого (подсудимого), а также свидетелей были описаны в приговоре весьма и весьма обстоятельно: каждому из них посвящено по несколько абзацев текста. А содержащиеся в уголовном деле протоколы следственных действий были охарактеризованы лишь фрагментарно - на нескольких строчках, без детального рассмотрения их содержания. В частности, в отношении результатов

32 Орлов Ю.К. Указ. соч. С. 161. 
контроля и записи переговоров было лишь отмечено, что они подтверждают фактическое общение в мае 2011 г. между людьми, говорящими между собой с абонентских номеров взяткодателя и взяткополучателя. При этом ни характер разговоров, ни их содержание, в отличие от изложенных в том же приговоре показаний, подробно не раскрываются ${ }^{33}$.

Аналогичная ситуация прослеживается, например, в приговоре Бутырского районного суда г. Москвы в отношении С., осужденной по ч. 4 ст. 159 УК РФ. Наряду с подробно охарактеризованными показаниями подсудимой, потерпевших и свидетелей в нем имеется указание на целый ряд протоколов осмотров документов, описанных весьма и весьма лаконично. Так, по поводу протокола осмотра выписки из домовой книги лишь кратко отмечается, что потерпевшая вместе с двумя детьми была зарегистрирована по указанному адресу на основании договора безвозмездного пользования ${ }^{34}$.

В приговоре Люблинского районного суда г. Москвы среди прочих доказательств фигури- рует протокол осмотра черного чехла от ножа, обнаруженного и изъятого в автомобиле и признанного вещественным доказательством. При этом судья вообще не счел необходимым упомянуть, зачем проводился этот осмотр и к каким результатам он привел ${ }^{35}$.

Следует заметить, что очень похожие проблемы наблюдаются и в близком к нам уголовно-процессуальном законодательстве стран СНГ. В частности, ст. 104 и 108 нового УПК Украины, делая акцент не на сущности протоколов, а на процессуальных правилах их составления, содержит также весьма краткие фоормулировки общего характера. Более детально протоколы следственных действий и судебного заседания регламентированы в ст. 99 УПК Республики Беларусь, ст. 122 УПК Казахстана и ст. 121 УПК Армении, где содержится перечень процессуальных действий, протоколы которых допускаются в качестве доказательств по уголовному делу. Однако представляется, что и эти правовые конструкции не способны разрешить всех обозначенных проблем.

\section{Библиография:}

1. Бойльке В. Уголовно-процессуальное право ФРГ / пер. с нем.; под ред. Л.В. Майоровой. Красноярск, 2004.

2. Божьев В.П., Лубенский А.И. Источники доказательств по уголовно-процессуальному законодательству СССР и других социалистических государств. - М., 1981.

3. Викторский С.И. Русский уголовный процесс. - М., 1912.

4. Владимиров Л.Е. Учение об уголовных доказательствах. Части общая и особенная. - СПб., 1910.

5. Выдря М.М. Вещественные доказательства в советском уголовном процессе. - М., 1955.

6. Вышинский А.Я. Теория судебных доказательств в советском праве. - М., 1950.

7. Галкин В.М. Средства доказывания в уголовном процессе. - М., 1967.

8. Духовской М.В. Русский уголовный процесс. - М., 1910.

9. Каминская В.И. Показания обвиняемого в советском уголовном процессе. - М., 1960.

10. Кипнис Н.М. Допустимость доказательств в уголовном судопроизводстве. - М., 1995.

11. Кокорев Л.Д., Кузнецов Н.П. Уголовный процесс: доказательства и доказывание. - Воронеж, 1995.

12. Курс советского уголовного процесса. Общая часть / под ред. А.Д. Бойкова, И.И. Карпеца. - M., 1989.

13. Лазарева В.А. Доказывание в уголовном процессе. - М., 2009.

14. Лившиц В.Я. Принцип непосредственности в советском уголовном процессе. - М., 1949.

15. Мотовиловкер Я.О. Показания и объяснения обвиняемого как средство защиты в советском уголовном процессе. - М., 1956.

16. Орлов Ю.К. Проблемы теории доказательств в уголовном процессе. - М., 2009.

17. Познышев С.В. Элементарный учебник русского уголовного процесса. - М., 1913.

18. Рахунов Р.Д. Теория и практика экспертизы в советском уголовном процессе. - М., 1953.

19. Строгович М.С. Курс советского уголовного процесса. Т. 1. - М., 1968.

20. Теория доказательств в советском уголовном процессе / отв. ред. Н.В. Жогин. Т. 2. - М., 1967.

\footnotetext{
33 http://www.mos-gorsud.ru.

34 http://sudrf.ru.
}

35 http://sudrf.ru. 
21. Теория доказательств в советском уголовном процессе / отв. ред. Н.В. Жогин. - М., 1973.

22. Уголовный процесс / под ред. Б.А. Викторова. - М., 1970.

23. Ульянова Л.Т. Оценка доказательств судом первой инстанции. - М., 1959.

24. Ульянова Л.Т. Предмет доказывания и доказательства в уголовном процессе России. - М., 2008.

25. Фельдштейн Г.С. Лекции по уголовному судопроизводству. - М., 1915.

26. Фойницкий И.Я. Курс уголовного судопроизводства. Т. 2. - СПб., 1996.

27. Чельцов М.А. Уголовный процесс. - М., 1948.

28. Якуб М.Л. Вещественные и письменные доказательства // Вопросы уголовного процесса в практике Верховного Суда СССР. - М., 1955.

\section{References}

1. Boil'ke V. Ugolovno-protsessual'noe pravo FRG / pod. red. L.V. Ma-iorovoi. - Krasnoyarsk, 2004.

2. Bozh'ev V.P., Lubenskii A.I. Istochniki dokazatel'stv po ugolovno-protsessual'nomu zakonodatel'stvu SSSR i drugikh sotsialisticheskikh gosudarstv. - M., 1981.

3. Viktorskii S.I.. Russkii ugolovnyi protsess. - M., 1912.

4. Vladimirov L.E. Uchenie ob ugolovnykh dokazatel'stvakh. Chasti: obshchaya i osobennaya. SPb., 1910.

5. Vydrya M.M. Veshchestvennye dokazatel'stva v sovetskom ugolovnom protsesse. - M., 1955.

6. Vyshinskii A.Ya. Teoriya sudebnykh dokazatel'stv v sovetskom prave. - M., 1950.

7. Galkin V.M. Sredstva dokazyvaniya v ugolovnom protsesse. - M., 1967.

8. Dukhovskoi M.V. Russkii ugolovnyi protsess. - M., 1910.

9. Kaminskaya V.I. Pokazaniya obvinyaemogo v sovetskom ugolovnom prot-sesse. - M., 1960.

10. Kipnis N.M. Dopustimost' dokazatel'stv v ugolovnom sudoproizvodstve. - M., 1995.

11. Kokorev L.D., Kuznetsov N.P. Ugolovnyi protsess: dokazatel'stva i dokazyvanie. - Voronezh, 1995.

12. Kurs sovetskogo ugolovnogo protsessa. Obshchaya chast' / pod red. A.D. Boikova, I.I. Karpetsa. M., 1989.

13. Lazareva V.A. Dokazyvanie v ugolovnom protsesse: uchebn. - M., 2009.

14. Livshits V.Ya. Printsip neposredstvennosti v sovetskom ugolovnom protsesse. - M., 1949.

15. Motovilovker Ya.O. Pokazaniya i ob"yasneniya obvinyaemogo kak sredstvo zashchity v sovetskom ugolovnom protsesse. - M., 1956.

16. Orlov Yu.K. Problemy teorii dokazatel'stv v ugolovnom protsesse. - M., 2009.

17. Poznyshev S.V. Elementarnyi uchebnik russkogo ugolovnogo protsessa. - M., 1913.

18. Rakhunov R.D. Teoriya i praktika ekspertizy v sovetskom ugolovnom protsesse. - M., 1953.

19. Strogovich M.S. Kurs sovetskogo ugolovnogo protsessa. T.1. - M., 1968.

20. Teoriya dokazatel'stv $v$ sovetskom ugolovnom protsesse / otv. red. N.V. Zhogin. T. 2. - M., 1967.

21. Teoriya dokazatel'stv v sovetskom ugolovnom protsesse / otv. red. N.V. Zhogin. - M., 1973.

22. Ugolovnyi protsess / pod red. B.A. Viktorova. - M., 1970.

23. Ul'yanova L.T. Otsenka dokazatel'stv sudom pervoi instantsii. - M., 1959.

24. Ul'yanova L.T. Predmet dokazyvaniya i dokazatel'stva v ugolovnom protsesse Rossii. - M., 2008.

25. Fel'dshtein G.S. Lektsii po ugolovnomu sudoproizvodstvu. - M., 1915.

26. Foinitskii I.Ya. Kurs ugolovnogo sudoproizvodstva. T. 2. - SPb., 1996.

27. Chel'tsov M.A. Ugolovnyi protsess. - M., 1948.

28. Yakub M.L. Veshchestvennye i pis'mennye dokazatel'stva // Voprosy ugolov-nogo protsessa v praktike Verkhovnogo Suda SSSR. - M., 1955. 